\title{
Finalidades da supervisão e perfil dos supervisores: um estudo de caso em Angola
}

\section{Supervision purposes and supervisor profiles: a case study in Angola}

\author{
Inês Monteiro, Flávia Vieira \\ Universidade do Minho, Centro de Investigação em Educação
}

\begin{abstract}
Resumo
Melhorar a qualidade das escolas e da formação dos professores continua a ser uma prioridade, sobretudo nos países em desenvolvimento. Uma das estratégias de melhoria é a supervisão pedagógica na formação inicial, importando investigar as práticas supervisivas nesse contexto. Foi com este objetivo que se iniciou em 2014 um estudo de caso na Escola de Formação de Professores Patrice Lumumba no Namibe, em Angola, que envolveu a recolha de perceções dos atores da supervisão dos 9 cursos de formação inicial da instituição, através do Questionário Sobre Perceções da Supervisão em Estágio. Com base em resultados parciais do estudo, discutem-se percepções sobre as finalidades da supervisão e o perfil do supervisor, e identificam-se desafios da formação nesse contexto.

Palavras-chave: Formação de professores, estágio, finalidades da supervisão, perfil do supervisor, problemas da supervisão.
\end{abstract}

\section{Introdução}

Na República de Angola, o processo de recuperação e estabilização económica e de desenvolvimento é ainda condicionado pelo significativo atraso registado no domínio educativo, sendo este país da Áfricasubsaariana um dos que regista maior taxa de analfabetismo e subescolarização. A Lei de Bases do Sistema de Educação 13/01 de Angola (Ministério da Educação de Angola, 2001) identifica um subsistema de formação de professores que destaca, no âmbito dos seus objetivos gerais, a necessidade de formar docentes com um perfil adequado à concretização daqueles dos objetivos da educação, a responsabilidade para a tarefa de educar as novas gerações e ainda a atualização e o aperfeiçoamento contínuo dos agentes educativos

É generalizado o consenso de que a educação é condição fundamental e indispensável para a dignidade e o progresso dos cidadãos, assim como para a sustentabilidade de qualquer país. Neste sentido, a formação inicial de professores constitui uma temática que tem atraído as mais diversas atenções por parte de académicos e investigadores e daqueles que têm em mãos as decisões políticas, sendo considerada um dos fatores que mais contribui para a melhoria da educação. Assim se compreende a importância do papel que as escolas de formação de professores representam no seio da comunidade educativa e o lugar central ocupado pelo estágio pedagógico como espaço de articulação entre a formação e a prática na formação inicial de professores.

Mas qual serão as finalidades ideais da supervisão pedagógica? E qual será o perfil ideal dos supervisores que ajudam na construção do perfil dos novos professores? Russell \& Martin (2014) debruçam-se sobre questões relacionadas com a formação de professores, alertando para a importância da reflexão e destacando igualmente a articulação do trabalho das disciplinas com o estágio e com o curso na sua totalidade como um dos elementos essenciais para a aprendizagem produtiva. Mas alcançar esta meta só será possível no momento em que estagiários e supervisores se interrogarem sobre as suas práticas de formação e aprendizagem, tentanto criar um espaço aberto de discussão sobre quais deverão ser as finalidades do processo supervisivo e o perfil dos agentes que o operacionalizam.

O estudo a seguir referido pretende contribuir para a compreensão destas questões, focando-se na supervisão em estágio. Foram auscultados os atores do estágio numa escola de formação em Angola, no sentido de produzir conhecimento útil e promover o debate no seio dessa comunidade educativa e em contextos de formação similares. Em seguida, apresentamos o contexto do estudo, o método de investigação e alguns resultados relativos a duas das dimensões estudades: finalidades da supervisão e perfil do supervisor. Finalmente, identificam-se desafios da formação nesse contexto, com base em problemas identificados pelos participantes.

\section{Contexto do Estudo}

No subsistema de ensino não-superior de Formação de Professores em Angola, que integra o conjuntos dos vários subsistemas do sistema educativo angolano, os estudantes percorrem um caminho da $10^{\mathrm{a}}$ à $13^{\mathrm{a}}$ Classes. Entre outras disciplinas, no último ano, realizam um Estágio Pedagógico, ficando habilitados para a docência no ensino pré-escolar e Magistério Primário e no ensino geral $\left(1^{\circ}\right.$ Ciclo até à $9^{\text {a }}$ Classe), podendo prosseguir estudos no ensino superior.

Na Escola de Formação de Professores (EFP) do Namibe existem 9 especialidades: Língua Portuguesa; Língua Francesa; Língua Inglesa; Matemática-Física; Biologia-Química; História-Geografia; Educação Física; Educação Visual e Plástica; Magistério Primário. O estágio é realizado em escolas da região ("escolas de aplicação”) e supervisionado por um professor da escola - o “professor tutor” (PT), em cujas turmas o estagiário leciona - e um professor da EFP - o "professor acompanhante" (PA). Este deve observar aulas (5 por trimestre, avaliando três) e discuti-las com o professor estagiário (PE), na presença do PT, preenchendo-se uma ficha de observação que é assinada por todos. O 
estagiário produz um relatório final de estágio, de acordo com os critérios estabelecidos no Regulamento de Estágio da EFP (2010), e a sua classificação tem em consideração a prática pedagógica e o relatório.

Embora seja reconhecida a importância da supervisão, ainda persiste uma certa ambiguidade em relação ao modo como deve ser operacionalizada e assim dar significado ao perfil do supervisor de forma a concretizar os objetivos formativos do processo de estágio. A tendência a reduzir esse processo ao momento da prática, ao modo como se deve estar perante uma turma na sala de aula e a um conjunto exaustivo de tarefas burocráticas, pode resultar numa desvalorização do processo educativo que o estágio deve representar (Pimenta \& Lima, 2012). Por outro lado, a falta de formação em supervisão faz com que as EFPs careçam de um plano que lhes permita recrutar supervisores com um histórico de práticas bem sucedidas e com competências de supervisão consolidadas.

\section{Método}

O estudo enquadra-se num paradigma naturalista da investigação educacional (Guba \& Lincoln, 1988), procurando compreender e problematizar a supervisão pedagógica a partir das perspetivas dos seus atores. É um estudo de caso de natureza descritiva e interpretativa, com três objetivos: (1) Caraterizar perceções dos professores acompanhantes, professores tutores e estagiários sobre as funções da supervisão, o perfil do supervisor, o processo supervisivo e as práticas educativas nas escolas; (2) Sinalizar boas práticas de supervisão e os fatores que as promovem na perspetiva dos seus atores; (3) Identificar constrangimentos e medidas de melhoria da supervisão no estágio pedagógico, na perspetiva dos intervenientes. A recolha de dados implicou a construção do Questionário Sobre Perceções da Supervisão em Estágio, administrado no contexto do estudo e preenchido de forma anónima. O instrumento, previamente testado com sujeitos que não participaram no estudo (na EFP do Lubango), é maioritariamente constituído por perguntas de resposta fechada e apresenta três versões semelhantes para os três grupos de participantes, permitindo a triangulação de percepções de forma a elevar a credibilidade dos resultados. Integra 8 secções:

A. Perfil académico e profissional do participante

B. Finalidades e atividades da supervisão de estágio (perceção da importância de um conjunto de finalidades/atividades e da sua presença nas práticas vivenciadas)

C. Perfil dos professores acompanhantes e professores tutores (perceção da importância de um conjunto de caraterísticas/ funções do supervisor e da sua presença nos supervisores dos cursos)

D. Práticas educativas nas escolas (perceção da importância de um conjunto de princípios da ação educativa e da sua presença no planeamento, observação e análise de aulas no estágio)

E. Competências profissionais a desenvolver no estágio (perceção da importância de um conjunto de competências e das que são mais desenvolvidas no estágio)
F. Problemas do estágio (perceção da gravidade de um conjunto de potenciais problemas)

G. Medidas para melhorar a supervisão no estágio (indicação livre de um máximo de quatro medidas)

H. Avaliação global da experiência de (supervisão do) estágio (numa escala de nove pontos: 1-Extremamente Negativa/ 9-Extremamente Positiva)

O questionário foi respondido por 560 participantes dos 9 cursos da instituição: 399 PE, 56 PA e 105 PT das escolas. Apresentamos em seguida resultados que se reportam às finalidades da supervisão e ao perfil do supervisor, identificando ainda alguns dos problemas do estágio. Os dados foram tratados com recurso à estatística descritiva (SPSS).

\section{Perceções do estágio: finalidades da supervisão,} perfil dos supervisores e problemas sentidos

A secção B do questionário solicitava aos participantes que indicassem a importância atribuída a um conjunto de finalidades da supervisão de estágio (visão ideal), usando uma escala de 4 opções ("Muito Importante", "Importante”, "Nada Importante”, "Sem Opinião”). As finalidades apresentadas incluem o apoio ao estagiário, a sua integração na escola, a promoção da autonomia, a promoção da inovação e a avaliação do desempenho.

O Quadro 1 apresenta os resultados correspondentes às respostas "Muito Importante" + "Importante”. Em geral, todas as finalidades são valorizadas. A percentagem de respostas nos três grupos varia entre $67.2 \%$ e $99 \%$ e as variações entre os grupos não são significativas, indiciando poucas diferenças de perspetiva.

\begin{tabular}{lccccc}
\hline \multirow{2}{*}{$\begin{array}{l}\text { Finalidades da Supervisão } \\
\text { (Muito Importantes ou Importantes) }\end{array}$} & $\begin{array}{c}\text { PA } \\
n\end{array}$ & PT & PE & T \\
\hline Avaliar o desempenho dos estagiários & 96.4 & 99.0 & 95.5 & 96.3 \\
\hline $\begin{array}{l}\text { Apoiar os estagiários na resolução de } \\
\text { problemas pedagógicos }\end{array}$ & 89.3 & 93.3 & 89.0 & 89.8 \\
$\begin{array}{l}\text { Fornecer bons modelos de ensino aos } \\
\text { estagiários }\end{array}$ & 91.1 & 94.3 & 86.5 & 88.4 \\
\hline $\begin{array}{l}\text { Ajudar os estagiários a analisar a } \\
\text { prática pedagógica }\end{array}$ & 85.7 & 95.2 & 86.7 & 88.2 \\
$\begin{array}{l}\text { Promover a inovação das práticas } \\
\text { pedagógicas nas escolas }\end{array}$ & 87.5 & 93.3 & 80.5 & 83.6 \\
$\begin{array}{l}\text { Ajudar os estagiários a desenvolver } \\
\text { seu próprio estilo de ensino }\end{array}$ & 69.6 & 78.1 & 81.2 & 79.5 \\
\hline $\begin{array}{l}\text { Promover a autonomia profissional dos } \\
\text { estagiários }\end{array}$ & 83.9 & 84.8 & 74.4 & 77.3 \\
\hline $\begin{array}{l}\text { Integrar os estagiários na cultura da } \\
\text { escola }\end{array}$ & 83.9 & 86.7 & 67.2 & 72.5 \\
\hline
\end{tabular}

Quadro 1. Finalidades da Supervisão: importância.

A avaliação do desempenho dos estagiários destaca-se como sendo a finalidade da supervisão mais importante para os inquiridos. A dimensão avaliativa da supervisão está muitas vezes associada a uma noção de supervisão como controlo e inspeção. Contudo, é necessário entender a supervisão num sentido mais amplo, como a teoria e a prática de regulação crítica de processos de ensino e aprendizagem (Vieira et al., 2010). Em certa medida, tal como defende Alarcão (2007), todos os que fazem parte do sistema educativo são supervisores e a 
supervisão deve ser um processo de auto/co-regulação em que todos têm a função de se entreajudarem e de contribuírem para o que entendem ser uma escola melhor.

Como se pode ver no Quadro 1, os participantes valorizam igualmente a dimensão do apoio ao estagiário nas práticas supervisivas, assim como a promoção da inovação, o que se concilia com a visão acima referida. No entanto, as finalidades relacionadas com a autonomia do estagiário e o desenvolvimento do seu próprio estilo de ensino são um pouco menos valorizadas, contrariamente ao fornecimento de modelos de ensino, o que pode indiciar algum afastamento de uma conceção emancipatória da supervisão (Vieira \& Moreira, 2011). Finalmente, a integração do estagiário na cultura da escola é a finalidade da supervisão menos valorizada pelos estagiários (67.2\%) e a menos valorizadas na globalidade dos resultados (72.5\%), o que levanta questões acerca da importância conferida a esta dimensão do processo de estágio enquanto processo de compreensão das culturas educativas em que ele se realiza.

Pedia-se também aos inquiridos que indicassem as finalidades da supervisão mais presentes nas práticas. Os resultados são apresentados no Quadro 2. A percentagem de respostas nos três grupos varia entre $20.1 \%$ e $73.2 \%$ e também não se verificam grandes discrepâncias entre eles, embora aqui os valores sejam muito mais baixos do que os valores relativos à importância conferida às mesmas finalidades. (Quadro 1). Por outras palavras, os sujeitos reconhecem um desfasamento entre as suas percepções ideais e a experiência vivida. Esse desfasamento está patente na Figura 1.

\begin{tabular}{lccccc}
\hline \multirow{2}{*}{$\begin{array}{l}\text { Finalidades da Supervisão } \\
\text { (Mais Presentes nas Práticas) }\end{array}$} & PA & PT & PE & T \\
\cline { 2 - 6 } & $\mathrm{n}$ & $\mathrm{n}$ & $\mathrm{n}$ & $\mathrm{n}$ \\
\hline Avaliar o desempenho dos estagiários & 73.2 & 67.6 & 65.2 & 66.4 \\
\hline $\begin{array}{l}\text { Ajudar os estagiários a analisar a } \\
\text { prática pedagógica }\end{array}$ & 41.1 & 52.4 & 41.4 & 43.4 \\
\hline $\begin{array}{l}\text { Apoiar os estagiários na resolução de } \\
\text { problemas pedagógicos }\end{array}$ & 30.4 & 49.5 & 37.6 & 39.1 \\
\hline $\begin{array}{l}\text { Fornecer bons modelos de ensino aos } \\
\text { estagiários }\end{array}$ & 41.1 & 37.1 & 28.8 & 31.6 \\
\hline $\begin{array}{l}\text { Integrar os estagiários na cultura da } \\
\text { escola }\end{array}$ & 33.9 & 33.3 & 23.3 & 26.3 \\
\hline $\begin{array}{l}\text { Ajudar os estagiários a desenvolver 0 } \\
\text { seu próprio estilo de ensino }\end{array}$ & 28.6 & 24.8 & 24.3 & 24.8 \\
\hline $\begin{array}{l}\text { Promover a inovação das práticas } \\
\text { pedagógicas nas escolas }\end{array}$ & 28.6 & 37.1 & 20.1 & 24.1 \\
\hline $\begin{array}{l}\text { Promover a autonomia profissional dos } \\
\text { estagiários }\end{array}$ & 32.1 & 21.0 & 22.8 & 23.4 \\
\hline
\end{tabular}

Quadro 2. Finalidades da Supervisão: presença.

A avaliação do desempenho dos estagiários é a finalidade da supervisão onde é menor o desfasamento entre a perspetiva ideal e a perceção das práticas. Assim, a maioria dos PA (73.2\%) destaca essa presença nas práticas, seguindo-se os PT (67.6\%) e os estagiários (65.2\%). Em todas as outras finalidades, relativas ao apoio, à inovação, à autonomização do estagiário e à integração na cultura escolar, verifica-se um desfasamento mais acentuado.

Este desfasamento pode indiciar insatisfação por parte dos participantes, na medida em que as práticas vivenciadas se afastam das suas perspetivas ideais. Por outro lado, também sugerem problemas ao nível das práticas. Para dar um exemplo, a função de apoio à resolução de problemas é essencial no sentido de fazer face a situações complexas e com o objetivo de tomar decisões que sejam satisfatórias e eficazes perante situações concretas, devendo o estagiário usufruir do know how daqueles que o supervisionam. No entanto, mais de metade dos participantes considera que o apoio à resolução de problemas está pouco presente na práticas vivenciadas.

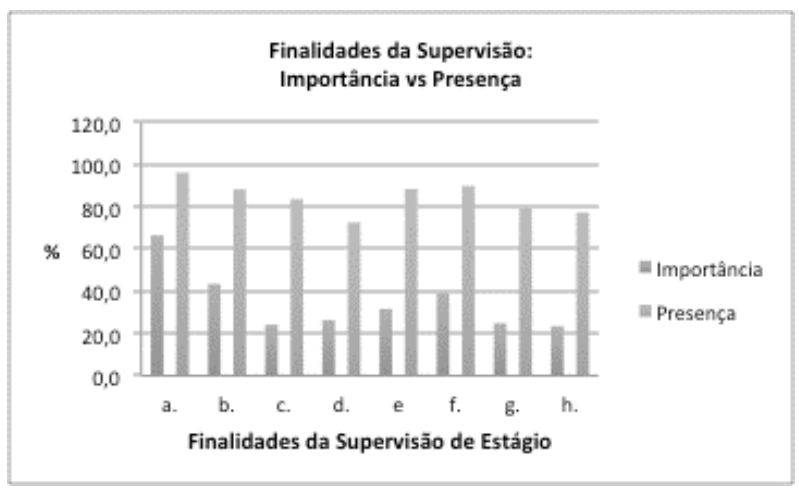

Legenda:

a. Avaliar o desempenho/ b. Apoiar a análise da prática / c. Promover a inovação / d. Integrar na cultura escolar / e. Fornecer bons modelos de ensino / f. Apoiar a resolução de problemas/ g. Ajudar no desenvolvimento do estilo de ensino / h. Promover a autonomia

Figura 1. Finalidades da Supervisão: importância vs. presença (totais).

Na secção C do questionário, incidente no perfil do supervisor, solicitava-se aos participantes que indicassem o grau de importância atribuído a um conjunto de competências dos supervisores (PT e PA), usando a mesma escala acima referida. O Quadro 3 apresenta os resultados, sendo que os valores nos três grupos variam entre $73,4 \%$ e $98.2 \%$, verificando-se uma valorização generalizada das competências apresentadas e, portanto, de um perfil de supervisor multifacetado. Uma vez mais, há variações pouco significativas entre os grupos, sugerindo que são poucas as diferenças de perspetiva entre os grupos. Observa-se, no entanto, que os resultados dos estagiários são ligeiramente mais baixos em todos os itens, à exceção do item relativo à capacidade de avaliar de forma justa, considerada importante por $91.7 \%$ dos estagiários. De facto, o processo de avaliação é sensível e complexo, podendo ser mal gerido por desconhecimento do modo como deve ser conduzido.

\begin{tabular}{lcccc}
\hline \multirow{2}{*}{$\begin{array}{l}\text { Perfil dos Supervisores (PT e PA) } \\
\text { (Muito Importantes ou Importantes) }\end{array}$} & $\begin{array}{c}\text { PA } \\
n\end{array}$ & PT & PE & T \\
\hline Gosto pelo ensino & 96 & $=105=399=560$ \\
\hline $\begin{array}{l}\text { Capacidade de planificar e avaliar o } \\
\text { processo de ensino-aprendizagem }\end{array}$ & 98.2 & 97.1 & 93.2 & 94.5 \\
\hline Capacidade de avaliar de forma justa & 89.3 & 93.3 & 90.7 & 92.0 \\
\hline
\end{tabular}




\begin{tabular}{llll}
\hline $\begin{array}{l}\text { Conhecimentos científicos da disciplina } \\
\text { em que orientam }\end{array}$ & 94.698 .189 .5 & 91.6 \\
\hline $\begin{array}{l}\text { Capacidade de diálogo, colaboração e } \\
\text { apoio }\end{array}$ & 96.497 .189 .091 .3 \\
\hline $\begin{array}{l}\text { Espírito de reflexão } \\
\begin{array}{l}\text { Capacidade de identificar e resolver } \\
\text { problemas }\end{array}\end{array}$ & 94.697 .688 .686 .789 .5 \\
$\begin{array}{l}\text { Conhecimentos de didática da disciplina } \\
\text { em que orientam }\end{array}$ & 98.298 .184 .588 .4 \\
\hline $\begin{array}{l}\text { Capacidade de observar e interpretar } \\
\text { dados da observação de aulas }\end{array}$ & 94.694 .385 .588 .0 \\
\hline $\begin{array}{l}\text { Capacidade de auxiliar na construção de } \\
\text { materiais de ensino-aprendizagem }\end{array}$ & 91.190 .581 .083 .8 \\
\hline $\begin{array}{l}\text { Conhecimentos sobre a formação e a } \\
\text { supervisão }\end{array}$ & 89.391 .480 .283 .2 \\
\hline $\begin{array}{l}\text { Espírito de autoformação e } \\
\text { desenvolvimento profissional }\end{array}$ & 89.393 .377 .982 .0 \\
\hline $\begin{array}{l}\text { Capacidade de relacionamento e } \\
\text { resolução de conflitos }\end{array}$ & 94.691 .477 .481 .8 \\
\hline \begin{tabular}{l} 
Abertura à inovação \\
\hline
\end{tabular}
\end{tabular}

Quadro 3. Perfil do Supervisor: importância.

O Quadro 4 apresenta as percepções dos participantes acerca das competências mais presentes nas práticas dos supervisores. As respostas nos três grupos variam entre $14.3 \%$ e $71.4 \%$ e, tal como anteriormente, também aqui se verifica um desfasamento acentuado entre a importância e a presença dessas competências, que podemos observar na Figura 2. Contudo, contrariando as análises anteriores, deparamo-nos com algumas variações entre os grupos, na ordem dos 20\%, nomeadamente em relação ao gosto pelo ensino, à abertura à inovação e à capacidade de avaliar de forma justa. Estas competências são mais percebidas nas práticas pelos PT do que pelos outros grupos. Com efeito, os PT parecem ter uma perceção ligeiramente mais positiva das práticas do que os outros dois grupos na maioria das competências apresentadas, e os estagiários são os que apresentam as percepções mais negativas. Saliente-se que, para os três grupos, a competência menos presente nos supervisores diz respeito à posse de conhecimentos sobre formação e supervisão, o que se relaciona com a falta de oportunidades de formação neste âmbito.

Tal como na análise anterior, também aqui podermos dizer que os resultados indiciam uma possível insatisfação por parte dos participantes, na medida em que as práticas vivenciadas se afastam das suas perspetivas ideais. Por outro lado, os resultados também sugerem problemas ao nível das práticas, uma vez que a ausência de competências de supervisão tem impacto na qualidade da formação. Coimbra (2013) revela que é comum os professores apontarem uma falta de uma supervisão sólida e capaz de promover um ensino de qualidade e um desenvolvimento profissional efetivo, demostrando que será importante o estreitamento das relações cooperativas entre as escolas de formação e as escolas que recebem os estágios. O supervisor deverá funcionar como uma espécie de interlocutor crítico, que questiona e problematiza a narrativa do estagiário. A meta será a construção de leituras alternativas da realidade que auxiliem o desenvolvimento de um conhecimento prático, ajustado às finalidades educativas a alcançar (Vieira \& Moreira, 2011).

\begin{tabular}{|c|c|}
\hline & $\begin{array}{lll}\text { PA } & \text { PT } & \text { PE Totais } \\
\end{array}$ \\
\hline $\begin{array}{l}\text { Pertil dos Supervisores (PT e PA) } \\
\text { (Mais Presentes nas Práticas) }\end{array}$ & $\begin{array}{cccc}\mathrm{n} & \mathrm{n} & \mathrm{n} & \mathrm{n} \\
=56 & =105 & =399 & =560\end{array}$ \\
\hline Gosto pelo ensino & $48,2 \quad 71,4 \quad 54,6 \quad 57,1$ \\
\hline $\begin{array}{l}\text { Capacidade de diálogo, colaboração e } \\
\text { apoio }\end{array}$ & $46,455,252,6 \quad 52,5$ \\
\hline Capacidade de avaliar de forma justa & $37,557,143,1 \quad 45,2$ \\
\hline $\begin{array}{l}\text { Conhecimentos científicos da disciplina } \\
\text { em que orientam }\end{array}$ & $53,342,6 \quad 44,8$ \\
\hline $\begin{array}{l}\text { Capacidade de planificar e avaliar o } \\
\text { processo de ensino-aprendizagem }\end{array}$ & $46,454,3 \quad 38,8 \quad 42,5$ \\
\hline $\begin{array}{l}\text { Capacidade de identificar e resolver } \\
\text { problemas }\end{array}$ & $35,754,3 \quad 35,6 \quad 39,1$ \\
\hline $\begin{array}{l}\text { Capacidade de observar e interpretar } \\
\text { dados da observação de aulas }\end{array}$ & $44,6 \quad 41,9 \quad 33,1 \quad 35,9$ \\
\hline $\begin{array}{l}\text { Conhecimentos de didática da disciplina } \\
\text { em que orientam }\end{array}$ & $44,6 \quad 41,932,3 \quad 35,4$ \\
\hline Espírito de reflexão & $41,145,7 \quad 31,3 \quad 35,0$ \\
\hline $\begin{array}{l}\text { Capacidade de relacionamento e } \\
\text { resolução de conflitos }\end{array}$ & $19,6 \quad 35,2 \quad 27,3 \quad 28,0$ \\
\hline $\begin{array}{l}\text { Espírito de autoformação e } \\
\text { desenvolvimento profissional }\end{array}$ & $21,4 \quad 36,2 \quad 22,8 \quad 25,2$ \\
\hline $\begin{array}{l}\text { Capacidade de auxiliar na construção de } \\
\text { materiais de ensino-aprendizagem }\end{array}$ & $23,2 \quad 36,2 \quad 20,8 \quad 23,9$ \\
\hline Abertura à inovação & $19,6 \quad 40,0 \quad 18,0 \quad 22,3$ \\
\hline $\begin{array}{l}\text { Conhecimentos sobre a formação e a } \\
\text { supervisão }\end{array}$ & $14,3 \quad 30,5 \quad 17,3 \quad 19,5$ \\
\hline
\end{tabular}

Quadro 4. Perfil do Supervisor: presença.

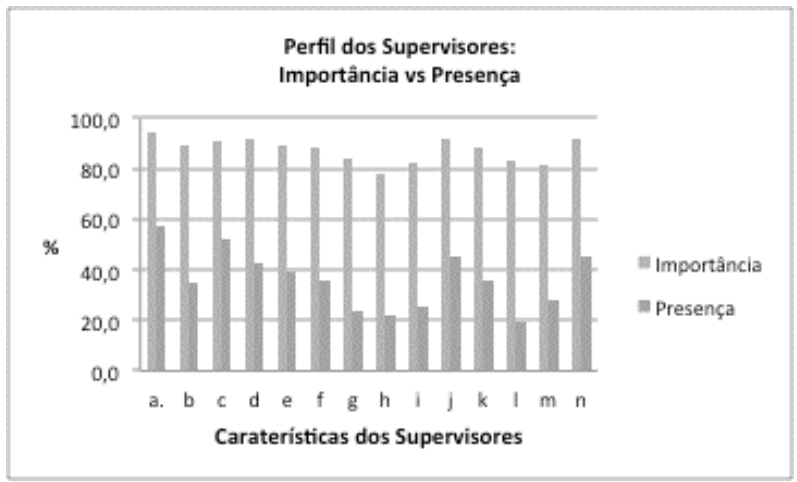

Legenda:

a. Gosto pelo ensino/ b. Espírito de reflexão/ c. Diálogo, colaboração e apoio/ d. Planificação e avaliação/ e. Identificação e resolução de problemas / f. Observação de aulas / g. Apoio na construção de materiais / h. Abertura à inovação/ i. Autoformação/ j. Conhecimento científico/ k. Conhecimento didático/ l. Conhecimento sobre formação e supervisão/m. Relacionamento e resolução de conflitos/n. Avaliação justa

Figura 2. Perfil do Supervisor: importância vs. presença (totais).

Na secção F do questionário, solicitava-se aos participantes que assinalassem problemas graves da supervisão, de acordo com a sua experiência, apresentando-se uma lista de 24 potenciais problemas, relativos a diversas dimensões do estágio. De forma a complementar as análises anteriormente realizadas, apresentam-se no Quadro 5 os resultados relativos a duas 
dimensões: formação dos supervisores e coordenação/ comunicação entre os supervisores da EFP e das escolas. Com se pode observar, uma percentagem significativa dos inquiridos reconhece a existência de problemas nestas dimensões, o que poderá explicar parcialmente os desfasamentos observados entre as perspetivas ideais dos participantes e as suas percepções das práticas (Figuras 1 e 2). Com efeito, a coordenação interinstitucional e a formação especializada dos supervisores são condições necessárias para que os supervisores desenvolvam um leque diversificado de competências e a supervisão pedagógica assuma, na prática, finalidades transformadoras e emancipatórias.

\begin{tabular}{lcccc}
\hline Problemas do estágio & PA & PT & PE & T \\
\cline { 2 - 5 } (considerados graves) & $\begin{array}{c}\mathrm{n} \\
=56\end{array}$ & $\begin{array}{c}\mathrm{n} \\
=105\end{array}$ & $\begin{array}{c}\mathrm{n} \\
=399\end{array}$ & $\begin{array}{c}\mathrm{n} \\
=560\end{array}$ \\
\hline $\begin{array}{l}\text { Falta de coordenação e } \\
\text { comunicação entre PA e PT }\end{array}$ & 42.9 & 54.3 & 63.4 & 59.6 \\
\hline $\begin{array}{l}\text { Falta de formação dos PT sobre } \\
\text { estratégias de supervisão }\end{array}$ & 71.4 & 54.3 & 55.6 & 57.0 \\
\hline $\begin{array}{l}\text { Falta de formação dos PA sobre } \\
\text { estratégias de ensino inovadoras }\end{array}$ & 37.5 & 49.5 & 53.1 & 50.9 \\
\hline $\begin{array}{l}\text { Falta de formação dos PT sobre } \\
\text { estratégias de ensino inovadoras }\end{array}$ & 53.6 & 49.5 & 50.9 & 50.9 \\
\hline $\begin{array}{l}\text { Falta de formação dos PA } \\
\text { sobre estratégias de supervisão }\end{array}$ & 37.5 & 43.8 & 49.9 & 47.5 \\
\hline
\end{tabular}

Quadro 5. Problemas do estágio: coordenação e formação

\section{Conclusões}

Escolas de formação focadas em melhorar a sua missão, a sua organização e os seus processos formativos necessitarão de analisar as suas práticas e intervir sobre elas no sentido de as melhorar. A EFP terá um papel fundamental na sensibilização dos seus agentes educativos, no sentido de reforçar o seu papel na formação de bons profissionais e na melhoria da educação escolar. Os resultados aqui apresentados revelam que existe ainda um longo caminho a percorrer neste sentido, verificando-se desfasamentos importantes entre aquilo que os atores da supervisão valorizam, e que está em consonância com o que se defende na literatura especializada, e aquilo que percebem nas práticas que vivenciam, as quais parecem ficar bastante aquém das suas perspetivas ideias. Entre os desafios que se colocam à instituição de formação perante esta situação, destacamos aqui dois que nos parecem essenciais e que foram identificados a partir das percepções dos participantes acerca dos problemas da supervisão: a coordenação /comunicação entre a EFP e as escolas, e a formação especializada dos supervisores (PT e PA) no âmbito das estratégias de supervisão e da inovação pedagógica.

A definição das finalidades da supervisão e do perfil do supervisor nos contextos da formação inicial de professores deverá surgir de reflexões conjuntas entre direções de escola/DPE e todos os intervenientes no processo de estágio, com vista a uma maior equidade nos processos de decisão e nos procedimentos a adotar. Estudos de investigação como este poderão ser muito importantes para despoletar a apoiar essas reflexões, mas só os atores educativos poderão torná-los verdadeiramente úteis.

\section{Referências}

Alarcão, I. (2007). Professores reflexivos em uma escola reflexiva (5 ${ }^{a}$ ed.). São Paulo: Cortez Editora.

Coimbra, M. N. (2013). Supervision and evaluation: teachers' perspectives. International Journal of Humanities and Social Science. 5(3), 65-71. Acedido a 28 junho, 2015 de http://www.ijhssnet.com/journals/Vol_3_No_5_March 2013/7.pdf

Guba, E., \& Lincoln, Y. (1988). Naturalistic and rationalistic enquiry. In J. Keeves (ed.), Educational research, methodology and measurement. An international handbook (pp. 81-85). Oxford: Pergamon Press.

Ministério da Educação de Angola (2001). Lei de Bases do Sistema de Educação 13/01. Acedido a 2 de novembro de 2013 em http://planipolis.iiep.unesco.org/upload/Angola/ Angola_Lei_de_educacao.pdf

Pimenta, S. M. \& Lima, M. Do S. (2012). Estágio e docência. $7^{\mathrm{a}}$ ed. São Paulo: Cortez.

Regulamento de Estágio Escola de Formação de Professores Patrice Lumumba, Namibe, 2010 (doc. interno).

Russell, T. \& Martin, A. K. (2014). A importância da voz pedagógica e da aprendizagem produtiva na formação inicial de professores. In M.A. Flores (org.), Formação e desenvolvimento profissional de professores: contributos internacionais (pp. 17-39). Coimbra: Almedina.

Vieira, F., Moreira, M. A., Barbosa, I., Paiva, M. \& Fernandes, I.S. (2010). No caleidoscópio da supervisão: Imagens da formação e da pedagogia ( $\left(2^{\mathrm{a}}\right.$ ed). Mangualde: Edições Pedago.

Vieira, F. \& Moreira, M. (2011). Supervisão e avaliação do desempenho docente: Para uma abordagem de orientação transformadora. Ministério da Educação Conselho Científico para a Avaliação de Professores. Cadernos do CCAP - 1. Acedido a 28 junho, 2015 de http://www.ccap.min!edu.pt/pub.htm 